\title{
Glibenclamide increases post-fatigue tension in slow skeletal muscle fibers of the chicken
}

\author{
Felipa Andrade $\cdot$ Xóchitl Trujillo $\cdot$ Enrique Sánchez-Pastor • \\ Rocío Montoya-Pérez • Alfredo Saavedra-Molina • \\ Mónica Ortiz-Mesina $\cdot$ Miguel Huerta
}

Received: 30 August 2010/Revised: 8 October 2010/Accepted: 25 October 2010/Published online: 16 November 2010

(C) The Author(s) 2010. This article is published with open access at Springerlink.com

\begin{abstract}
In contrast to fast-twitch skeletal muscle fibers of the chicken, slow-twitch fibers are fatigue-resistant. In fast fibers, the fatigue process has been related to $\mathrm{K}_{\mathrm{ATP}}$ channels. In the present study, we investigated the action of glibenclamide (an anti-diabetic sulphonylurea that acts on $\mathrm{K}_{\text {ATP }}$ channels) on fatigued slow skeletal muscle, studying twitch and tetanus tension after inducing the muscle to fatigue by continuous electrical stimulation. Our results showed that glibenclamide $(150 \mu \mathrm{M})$ increased post-fatigue twitch tension by about $25 \%$ with respect to the fatigued
\end{abstract}

Communicated by I.D. Hume.

F. Andrade

Instituto Tecnológico de Colima, Avenida Tecnológico No. 1,

C.P. 28976 Villa de Álvarez, Colima, México

X. Trujillo · E. Sánchez-Pastor · R. Montoya-Pérez ·

M. Ortiz-Mesina - M. Huerta

Unidad de Investigación Dr. Enrico Stefani del Centro

Universitario de Investigaciones Biomédicas,

Universidad de Colima, Apartado Postal No. 11,

C.P. 28000 Colima, Colima, México

R. Montoya-Pérez

Facultad de Ciencias Médicas y Biológicas,

Universidad Michoacana de San Nicolás de Hidalgo,

Morelia, Michoacán, México

A. Saavedra-Molina

Instituto de Investigaciones Químico-Biológicas,

Universidad Michoacana de San Nicolás de Hidalgo,

Morelia, Michoacán, México

\section{Trujillo ( $\square)$}

Unidad de Investigación Enrico Stefani, Centro Universitario de Investigaciones Biomédicas, Universidad de Colima,

Avenida 25 de julio \# 965, Colonia Villa San Sebastián, Apartado Postal No. 11, C.P. 28040 Colima, Colima, México e-mail: rosio@ucol.mx condition $(P<0.05)$. In addition, glibenclamide $(150 \mu \mathrm{M})$ increased post-fatigue tetanic tension $(83.61 \pm 15.7 \%$ in peak tension, and $85.0 \pm 19.0 \%$ in tension-time integral, $P=0.02$, and 0.04 , respectively; $n=3$ ). Moreover, after exposing the muscle to a condition that inhibits mitochondrial ATP formation in order to activate $\mathrm{K}_{\mathrm{ATP}}$ channels with cyanide $(10 \mathrm{mM})$, tension also diminished, but in the presence of glibenclamide the effect produced by cyanide was abolished. To determine a possible increase in intracellular calcium concentration, the effects of glibenclamide on caffeine-evoked contractures were explored. After muscle pre-incubation with glibenclamide $(150 \mu \mathrm{M})$, tension of caffeine-evoked contractures increased $(6.5 \pm 1.5 \%$ in maximal tension, and $5.9 \pm 3.8 \%$ in tension-time integral, $P<0.05$ ). These results suggest a possible role of $\mathrm{K}_{\text {ATP }}$ channels in the fatigue process, since glibenclamide increases twitch and tetanus tension in fatigued slow muscle of the chicken and during metabolic inhibition, possibly by increasing intracellular calcium.

Keywords Glibenclamide Fatigue $\cdot$ Skeletal muscle

\section{Introduction}

Slow-twitch skeletal muscle, in contrast to fast-twitch muscle is more resistant to fatigue. During muscle contraction, ATP is necessary and muscle demand increases when it is continuously stimulated; so its availability is reduced through fatiguing exercise. There are ionic channels capable of sensing the demands of ATP as ATP-dependent potassium channels $\left(\mathrm{K}_{\mathrm{ATP}}\right)$ (Noma 1983; Inagaki and Seino 1998). These $K_{\text {ATP }}$ channels are inhibited when intracellular ATP concentration increases to $\mathrm{mM}$ levels. 
During fatigue, intracellular ATP decreases leading to a reduction in ATP hydrolysis in order to protect the cells, thus $\mathrm{K}_{\mathrm{ATP}}$ channels are sensors of ATP and ADP intracellular rate (Inagaki and Seino 1998). The activation of $\mathrm{K}_{\mathrm{ATP}}$ channels succeeds when the cells are compromised in ATP-demanding functions (Yokoshiki et al. 1997) such as fatigue or metabolic inhibition. These channels couple the metabolic state of the cell to its electrical activity and they have been reported in cardiac tissue (Noma 1983) and pancreatic tissue functionality linked to insulin secretion (Ashcroft et al. 1984; Cook and Hales 1984; Rorsman and Trube 1985), in amphibian skeletal muscle (Spruce et al. 1985, 1987), in mammalian skeletal muscle (Burton et al. 1988), in avian fast skeletal muscle (Thomas and Hume 1993; Fosset et al. 1995), in smooth muscle (Davies et al. 1991), and in the central nervous system (Ashford et al. 1988).

Some authors have explored the role of $\mathrm{K}_{\mathrm{ATP}}$ channels in skeletal muscle using agonists of these channels, suggesting that their activation is involved in the diminution of force when muscle is fatigued (Weselcouch et al. 1993; Light and French 1994; Wickenden et al. 1996; Matar et al. 2000, 2001). However, other authors used $\mathrm{K}_{\text {ATP }}$ channel antagonists, such as glibenclamide (a broadly used antidiabetic drug), but did not find effects on fatigue in their results (Light et al. 1994; Van Lunteren et al. 1998; Matar et al. 2000; Gong et al. 2003). Others reported acceleration of fatigue (Comtois et al. 1994), or an increase in tetanic force and in intracellular $\mathrm{Ca}^{2+}$ levels (Duty and Allen 1995).

Thus, in the present paper, the effects of glibenclamide on twitch and tetanus tension of fatigued slow skeletal muscle fibers of the chicken, as well as its action during metabolic inhibition (low ATP), were studied.

\section{Methods}

Ethical approval

Chickens were used in accordance with the Institute for Laboratory Animal Research (ILAR) (1996) Guide for the Care and Use of Laboratory Animals and the Ethics Committee of the Centro Universitario de Investigaciones Biomedicas of the Universidad de Colima approved the protocol. To minimize animal pain and distress, as well as for muscle extraction, chickens were previously anesthetized with chloroform, followed by cervical dislocation and decapitation, ensuring a fast and complete separation of the head from the body [American Veterinary Medical Association AVMA (2007) Guidelines on Euthanasia].

\section{Dissection}

The anterior latissimus dorsi (ALD) muscle was chosen for this investigation as it is exclusively made up of slow muscle fibers. Muscles were carefully dissected out, together with a piece of the humerus bone and a portion of the vertebral cord from 1 to 2-week-old chickens (arbor acres). The vertebral cord was pinned at the bottom of the experimental chamber and 3.0 surgical silk threads were tied around the humerus bone to attach muscle bundle (1-2 mm thick) distal end to a force transducer (Grass FT03, West Warwick, RI, USA) by means of a lightweight wire. To record force, the transducer was wired to an amplifier (Cyberamp 320, Axon Instruments, Foster City, CA, USA) and connected to an analog-to-digital converter (DMA TL-1, Axon Instruments) with a $5 \mathrm{~Hz}$ sampling rate. Data were acquired using the subroutine Clampex of pClamp 8.0 (Axon Instruments) in a desk computer.

\section{Fatigue protocols}

To establish a fatigue protocol in the slow latissimus dorsi muscle, different electrical stimulation frequencies were used to produce twitches or tetanus. Twitches were evoked by repetitive supramaximal $300 \mathrm{~ms}$ square-wave pulses (Grass S-88 stimulator and SIU-5 stimuli isolation unit) at $0.2 \mathrm{~Hz}$ until bundle contractions were approximately $30-40 \%$ of the control contraction (about $60 \mathrm{~min}$ ). Tetanic contractions were evoked every $10 \mathrm{~s}$ by trains of $10 \mathrm{~ms}$ pulses delivered at 5 (low frequency fatigue) or 50 (high frequency fatigue) $\mathrm{Hz}$ for $5 \mathrm{~s}$ until force fell to around $30 \%$ of initial tension (about $10 \mathrm{~min}$ ). Pulses were delivered across platinum wire electrodes situated at either side of the muscle. Each protocol consisted of a period with initial stimulation to induce fatigue (about $30 \%$ of initial tension), after which glibenclamide was applied to the bath for $5 \mathrm{~min}$, maintaining the stimulation. It was followed by washout with Ginsborg normal saline. After drug washout, electrical stimulation continued to record tension for $15 \mathrm{~min}$ for post-fatigue analysis.

\section{Caffeine contractures}

Caffeine-evoked-tension has been reported to be due to calcium release from the sarcoplasmic reticulum (SR) (Caputo 1966; Klein et al. 1990; Huerta and Stefani 1981; Muñiz et al. 1992), but in slow fibers, Huerta and Stefani (1981) and Shabala et al. (2008) suggest that caffeine also opens the L-type $\mathrm{Ca}^{2+}$ channels from the sarcolemma, assuring $\mathrm{Ca}^{2+}$ entry from the external media. Thus, contractures in the ALD muscle were induced by applying $8 \mathrm{mM}$ caffeine. The time course of caffeine contractures 
was $5 \mathrm{~min}$. Protocol consisted of $5 \mathrm{~min}$ exposure to caffeine contracture followed by a resting period of $30 \mathrm{~min}$ including $5 \mathrm{~min}$ of glibenclamide exposure. After that, 5 min caffeine $(6 \mathrm{mM})$ contracture was recorded in the presence of glibenclamide. After $30 \mathrm{~min}$ washout, a final caffeine contracture was obtained.

\section{Solutions}

Muscles were immersed in normal Ginsborg saline (Ginsborg 1960; Page 1969) composed of (in $\mathrm{mM}$ ): $167 \mathrm{NaCl}, 5$ $\mathrm{KCl}, 2 \mathrm{MgCl}_{2}, 5 \mathrm{CaCl}_{2}, 2$ imidazole-chloride, and $\mathrm{pH}$ was adjusted to 7.4. Normal Ginsborg was supplemented with $2 \mathrm{~g} / \mathrm{l}$ glucose, but mannitol instead of glucose was used in the experimental fatigue to prevent blocking of $\mathrm{K}_{\mathrm{ATP}}$ channels by glucose (Tsuura et al. 1993). Solutions containing glibenclamide, caffeine, cyanide or verapamil (Sigma Co., St. Louis, MO, USA) were obtained by adding the proper volume of stock solutions (glibenclamide $2 \mathrm{mM}$ in $\mathrm{NaOH} 0.05 \mathrm{M}, \mathrm{NaCN} 100 \mathrm{mM}$ in water, caffeine $100 \mathrm{mM}$ in water and verapamil $100 \mathrm{mM}$ ) to the mannitol Ginsborg solution. Solutions entered via a three-way tap located at one end of the central channel of the experimental chamber.

\section{Statistical methods}

Tension was measured as the maximum tension from the basal line to the peak before, during, and after addition of the experimental drug (peak tension) and tension-time integral was obtained from the area under the twitch profile. Each experimental condition was then compared. Data analysis were carried out using the pClamp 8.0 (Axon Instruments, Foster City, CA, USA) and subroutine and graphs were elaborated using Sigmaplot 8.0 software. Results were expressed as means \pm S.E.M. followed by the $n$ value. Mean comparison was applied by Student $t$ test, accepting a significant effect when $P$ was $<0.05$.

\section{Results}

Glibenclamide increases twitch tension of fatigued slow skeletal muscle fibers

There are some reports indicating the presence of $\mathrm{K}_{\mathrm{ATP}}$ channels in the membranes of mammalian and avian fast skeletal muscle fibers and it has been suggested that these kinds of channels may have a functional role in muscular fatigue. However, the physiological role of these $\mathrm{K}^{+}$ channels during the fatigue process and metabolic inhibition is not yet fully established (Davies et al. 1991; Nichols and Lederer 1991; Fosset et al. 1995; Minami et al. 2004; Cifelli et al. 2007).

To establish a fatigue model, we used slow skeletal muscle fibers of the chicken and found that this kind of muscle fiber became fatigued after $60 \mathrm{~min}$ of stimulation with a low frequency $(0.2 \mathrm{~Hz})$. This represents a $60 \%$ reduction in the control. Once the fatigue model was established, we studied the effect of glibenclamide (a $\mathrm{K}_{\text {ATP }}$ channel blocker, Van Lunteren et al. 1998), during low frequency fatigue. Glibenclamide blocks $\mathrm{K}_{\mathrm{ATP}}$ channels at a concentration of $100 \mu \mathrm{M}$ (Light and French 1994). Figure 1a shows a representative trace of an experiment in which the effect of glibenclamide $(150 \mu \mathrm{M})$ on slow skeletal muscle fibers of the chicken was examined. The first twitch shown corresponds to the start of the experiment (control). The second one shows the single twitch once the fibers were fatigued according to the fatigue model. The third twitch corresponds to the recording after the addition of glibenclamide $(150 \mu \mathrm{M})$, in which an increase in tension when compared with the twitch in the fatigued state can be observed. This increase is around $25 \%$ higher than the tension in fatigued condition $(P<0.05)$. Finally, the fourth twitch corresponds to the twitch once the glibenclamide was washed out from the bath.

In Fig. 1b, the results obtained using glibenclamide on fatigued muscle fibers are shown in the graph. Mean tension recorded during fatigue was approximately $45 \%$ $(44.54 \pm 7.66 \%$ in averaged peak tension and $45.94 \pm$ $8.79 \%$ in tension-time integral), with respect to the control $(P<0.05)$. When glibenclamide was added to the bath, averaged peak tension increased to $69.86 \pm 6.09 \%$, and tension-time integral increased to $69.53 \pm 8.20 \%$. Both were statistically different with respect to fatigued tension $(P<0.05)$. After glibenclamide washout, averaged peak tension was $56.13 \pm 9.68 \%$ and tension-time integral was $57.42 \pm 8.17 \%(n=4)$. These results show that glibenclamide, a $\mathrm{K}_{\mathrm{ATP}}$ channels blocker, increases tension of low frequency fatigued muscle fibers.

Glibenclamide increases tension of tetanus in fatigued muscle fibers

Another way to induce fatigue in these muscles is by producing tetanic contractions. We used low $(5 \mathrm{~Hz})$ and high frequencies $(50 \mathrm{~Hz})$ to generate tetanus. Using these protocols tension was diminished $70-80 \%$ after $10 \mathrm{~min}$ of stimulation, depending on stimulation frequency. Similar results have been reported for fast skeletal muscle fibers showing a diminution of $70 \%$, although this diminution was reached in less time (Duty and Allen 1995).

In Fig. 2a representative traces show the effect of glibenclamide $(150 \mu \mathrm{M})$ on tetanic tension $(5 \mathrm{~Hz})$ of fatigued 
Fig. 1 Effects of $150 \mu \mathrm{M}$ glibenclamide on twitch at $60 \%$ of fatigue. a In representative trace 1 , the recorded tension at the start of the experiment. In trace 2 , the recorded tension approximately $1 \mathrm{~h}$ after stimulating at a frequency of $0.2 \mathrm{~Hz}$. In trace $3,5 \mathrm{~min}$ in the presence of glibenclamide increased the tension in the fatigued muscle. Trace 4 shows the recorded tension $10 \mathrm{~min}$ after glibenclamide washout. b Graphs showing the effects of glibenclamide on single twitch tension. Glibenclamide produced a significant increase in both total and maximal tension of twitches in fatigued muscle fibers $(n=4)$. Asterisks indicate $P<0.05$
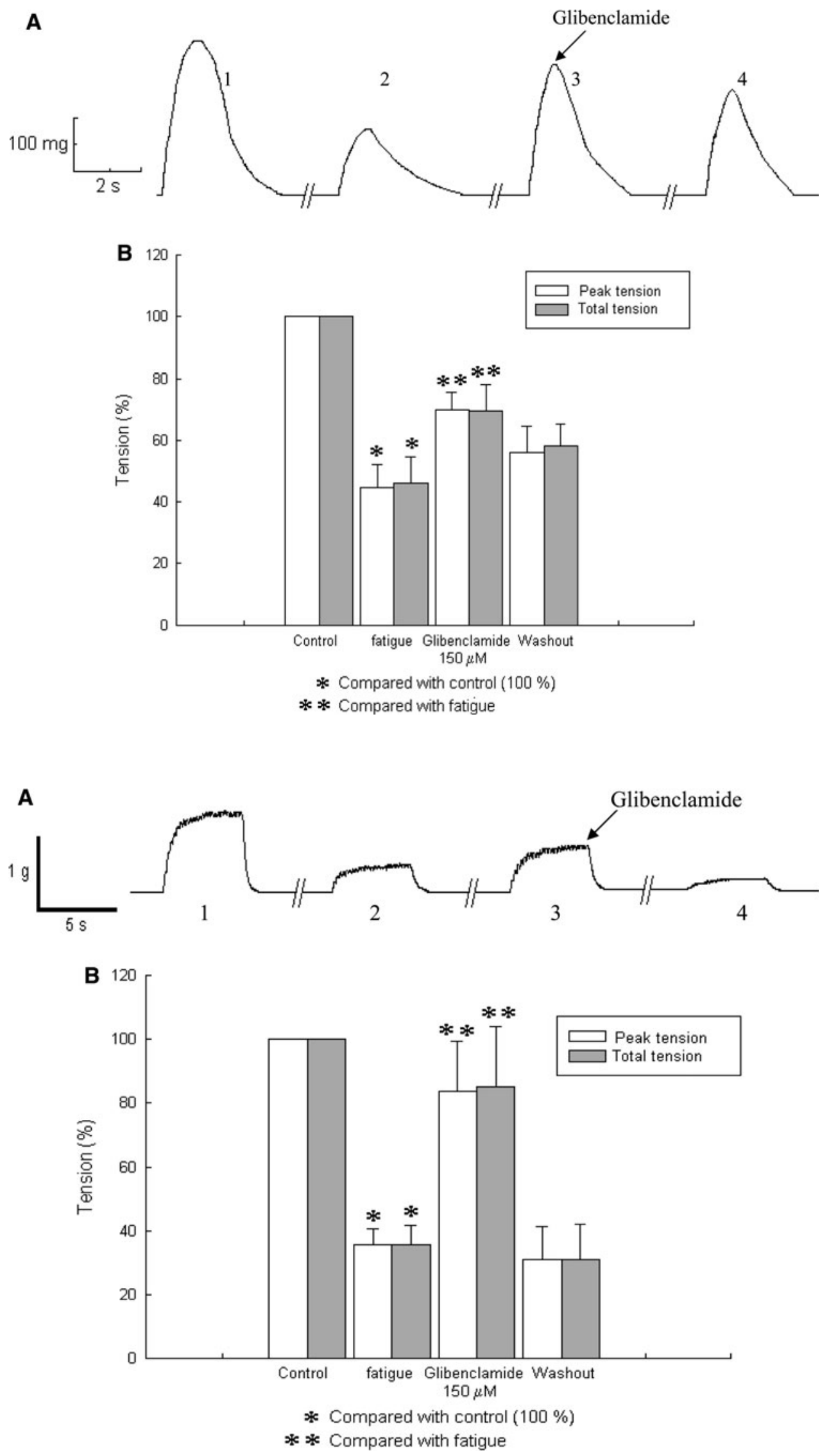
muscle. In representative trace 1 , tetanus recorded at the beginning of the experiment is shown. In trace 2, tetanus recorded after $10 \mathrm{~min}$ of stimulation is shown. In trace 3 , tetanic tension recorded in the presence of glibenclamide is shown. Under this condition tetanic tension is increased, reversing the fatigue. Trace 4 shows tetanic tension recorded after glibenclamide washout, in which the muscle was further fatigued.

Graphs illustrating the effect of glibenclamide $(150 \mu \mathrm{M})$ on tetanic tension in fatigued muscle fibers are shown in Fig. 2b. Averaged tension was reduced during fatigue by almost $70 \%(35.64 \pm 4.79 \%$ in peak tension and $35.81 \pm 5.99 \%$ in tension-time integral) with respect to the control $(P=0.00001, P=0.00004$, respectively; $n=3)$. In the presence of glibenclamide tetanic tension increased to $83.61 \pm 15.71 \%$ in peak tension and to $85.06 \pm 19.00 \%$ in tension-time integral $(P=0.0267, P=0.0484$ respectively; $n=3$ ). These data correspond to traces 2 and 3 from Fig. 2a. After glibenclamide washout the fatigue process started diminishing tetanic tension again (Figs. 2a, 4).

When a fatigue protocol with high stimulation frequencies was used, we observed a similar effect with glibenclamide $(150 \mu \mathrm{M})$ after fatigue. The graphs for this effect are shown in Fig. 3. Some groups have used frequencies as high as $100 \mathrm{~Hz}$ (e.g., Duty and Allen 1995); but when we used $100 \mathrm{~Hz}$ or even $70 \mathrm{~Hz}$ the muscle suffered irreversible damage and therefore we chose to use $50 \mathrm{~Hz}$. Under these conditions, tetanic tension during fatigue was reduced to $12.68 \pm 4.53 \%$ in peak tension and to $10.41 \pm 4.98 \%$ in tension-time integral with respect to the control. These reductions were statistically significant, having values of $P=0.000001, P=0.000002$, respectively, for peak tension and tension-time integral $(n=3)$.
When glibenclamide $(150 \mu \mathrm{M})$ was added, peak tension increased to $30.58 \pm 5.00 \%$ with respect to the fatigued state, and tension-time integral was $28.96 \pm 5.64 \%$ $(n=3)$. Student $t$ test showed significance in these results indicating a statistical difference in both parameters $(P=0.03$ in peak tension and $P=0.04$ in tension-time integral of the tetanus). Thus, our results show that fatigue induced with high frequencies was also reverted in the presence of glibenclamide.

Effects of glibenclamide on caffeine contractures in slow skeletal muscle fibers

To examine whether or not the effects of glibenclamide were mediated by an increased $\mathrm{Ca}^{2+}$ release from SR, the effect of this drug on contractures induced by caffeine, an alkaloid that mainly induces $\mathrm{Ca}^{2+}$ release from the SR (Caputo 1966; Huerta and Stefani 1981; Muñiz et al. 1992; Shabala et al. 2008) was studied. Moreover, in slow muscle fibers caffeine can open L-type $\mathrm{Ca}^{2+}$ channels in the sarcolemma (Huerta and Stefani 1981; Shabala et al. 2008). In caffeine-induced contractures $(8 \mathrm{mM})$, the addition of glibenclamide $(150 \mu \mathrm{M})$ caused an increase in amplitude of the contracture with respect to the control. Figure 4a shows a representative trace obtained in this set of experiments. The increase in caffeine contracture observed in the presence of glibenclamide was $6.55 \pm 1.57 \%$ in maximal tension and $5.93 \pm 3.86 \%$ in tension-time integral $(P<0.05 ; n=3)$. These effects were reversible after glibenclamide washout, since contracture returned to the initial tension. In Fig. 4b results obtained in these experiments are shown in the graph. They suggest that, at least partly, glibenclamide increased the tension of these slow
Fig. 3 Effects of glibenclamide on tetanic force generated with $50 \mathrm{~Hz}$ of stimulation pulses. Glibenclamide increased tetanic tension of fatigued muscle fibers. Asterisks indicate $P<0.05$

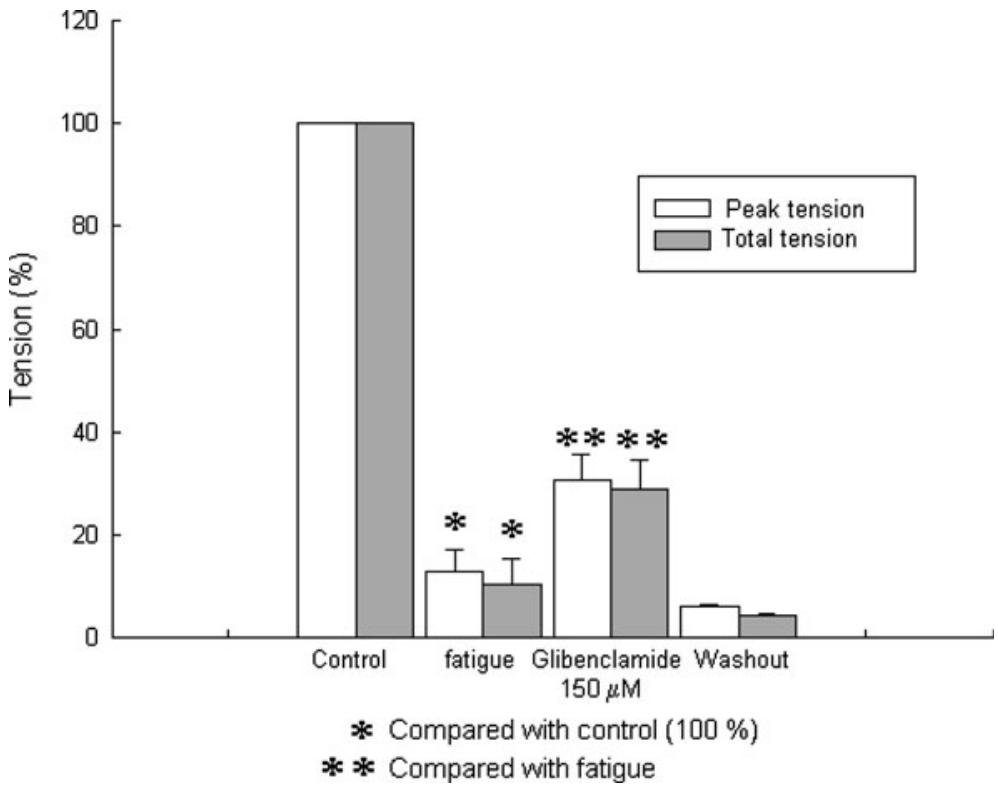


Fig. 4 Effects of glibenclamide on caffeine contractures. a Representative traces obtained by inducing contractures with caffeine $8 \mathrm{mM}$ before and after the addition of glibenclamide. Inferior trace corresponds to control caffeine contracture and superior trace corresponds to caffeine contracture in the presence of glibenclamide $(150 \mu \mathrm{M})$. b Graphs showing the effect of glibenclamide $(150 \mu \mathrm{M})$ on caffeine contractures. Presence of glibenclamide increases caffeine-induced tension with respect to the control $(P<0.05$; $n=3)$. Asterisks indicate $P<0.05$
A
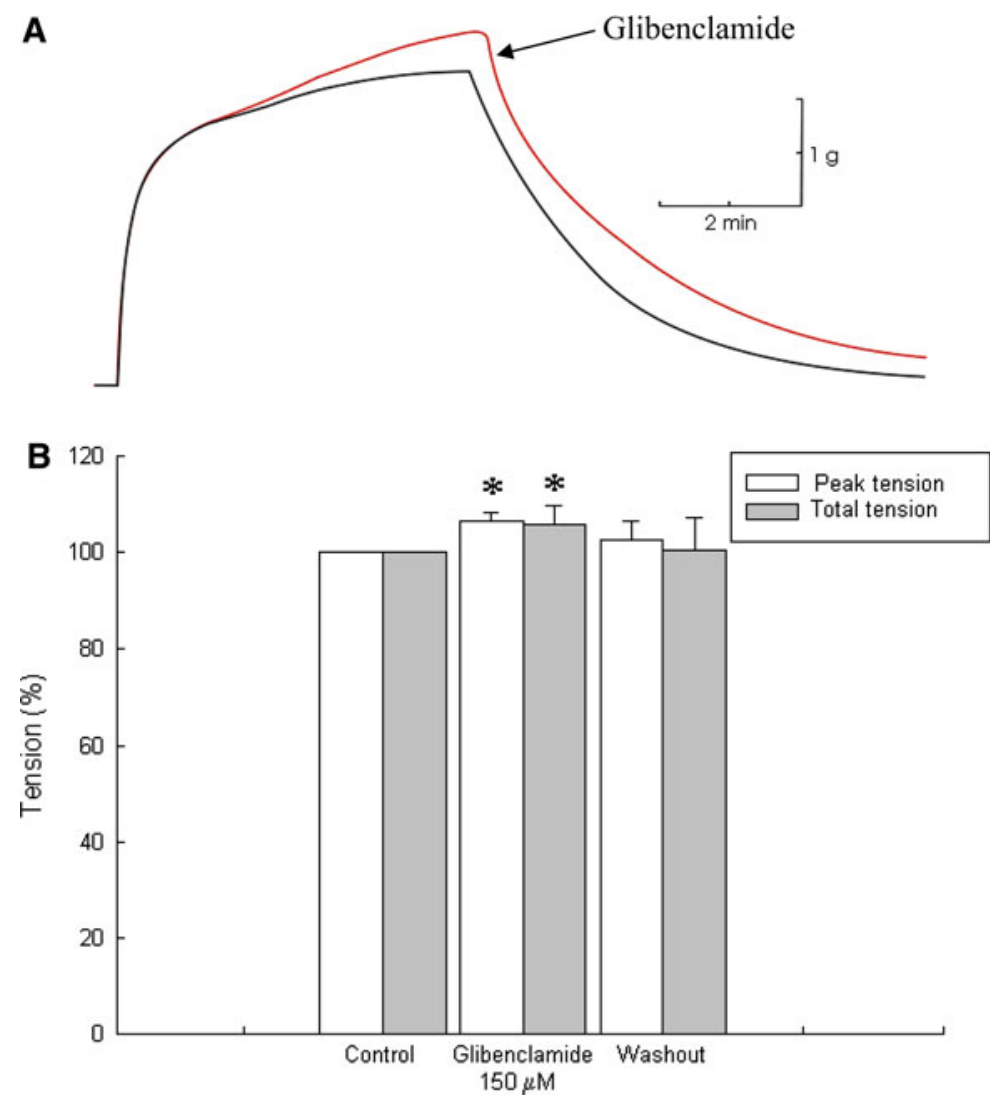

skeletal muscle fibers by opening $\mathrm{Ca}^{2+}$ channels in the sarcolemma, since the plateau depends on external $\mathrm{Ca}^{2+}$ (Huerta and Stefani 1981).

In order to discard the participation of sarcolemmal L-type $\mathrm{Ca}^{2+}$ channels in the effect observed with caffeine plus glibenclamide, caffeine contractures were induced in the presence of glibenclamide $(150 \mu \mathrm{M})$ after blocking these channels with verapamil $(10 \mu \mathrm{M})$. In these experiments, after blocking the L-type $\mathrm{Ca}^{2+}$ channels, a significant increase in both peak tension and tension-time integral (data not shown) was still observed, supporting our hypothesis that the increase in tension caused by glibenclamide is due to an increase in $\mathrm{Ca}^{2+}$ release from the SR.

Glibenclamide blocks the effect of metabolic inhibition on muscle tension

The model for metabolic inhibition induced by cyanide was used according to Gramolini and Renaud (1997) to avoid ATP production and thus to decrease intracellular levels of ATP. Under these conditions the effect of glibenclamide on twitches generated by $0.2 \mathrm{~Hz}$ pulses were explored.

Results obtained in this experimental series are shown in Fig. 5. Incubation with cyanide $(10 \mathrm{mM})$ for $5 \mathrm{~min}$ produced a rapid diminution in twitch tension as shown in Fig. 5a (second twitch) with respect to the control. This diminution in twitch tension was statistically significant $(P<0.05$; Fig. 5 b, second bars $)$. After cyanide washout, twitch tension recovered its initial levels. Then, cyanide plus glibenclamide $150 \mu \mathrm{M}$ was added to the bath for 5 min. In Fig. 5a the third twitch shows tension recorded after $5 \mathrm{~min}$ in the presence of cyanide plus glibenclamide and tension similar to that recorded at the start of the experiment (first twitch) can be observed. Thus, the presence of glibenclamide blocked the cyanide-produced effect on force, by avoiding the diminution in tension caused by cyanide alone. The fourth twitch corresponds to the final washout, showing that twitch tension was maintained at values similar to the control condition.

\section{Discussion}

$\mathrm{K}_{\mathrm{ATP}}$ channels are involved in the coupling of the metabolic state of the cell to its electric activity. In skeletal muscle, it has been shown that $\mathrm{K}_{\mathrm{ATP}}$ channels have a role in force reduction during some metabolic stress states such as anoxia, ischemia, fatigue, and during metabolic inhibition to preserve ATP and thus prevent muscular damage (Weselcouch et al. 1993; Wickenden et al. 1996; Matar et al. 2000). There are some reports indicating the presence of $\mathrm{K}_{\mathrm{ATP}}$ channels in the membranes of mammalian and 
Fig. 5 Effects of glibenclamide on twitch tension in skeletal muscle fibers during metabolic inhibition by cyanide. a In trace 1 a twitch at the start of the experiment (control) is shown. Trace 2 shows the twitch after $5 \mathrm{~min}$ in the presence of cyanide $10 \mathrm{mM}$ (metabolic inhibition). This effect was totally reversible after cyanide washout. In trace 3 , the presence of glibenclamide in the bath avoided the diminution in tension produced by cyanide. In trace 4 , the twitch tension at the end of the experiment is similar to that recorded at the start. b Graphs for the effect of glibenclamide on twitch in metabolic inhibition. Twitch tension notably diminished in the presence of cyanide with respect to the control $(P<0.05)$. Presence of glibenclamide avoided the effect of metabolic inhibition with cyanide. Asterisks indicate $P<0.05$
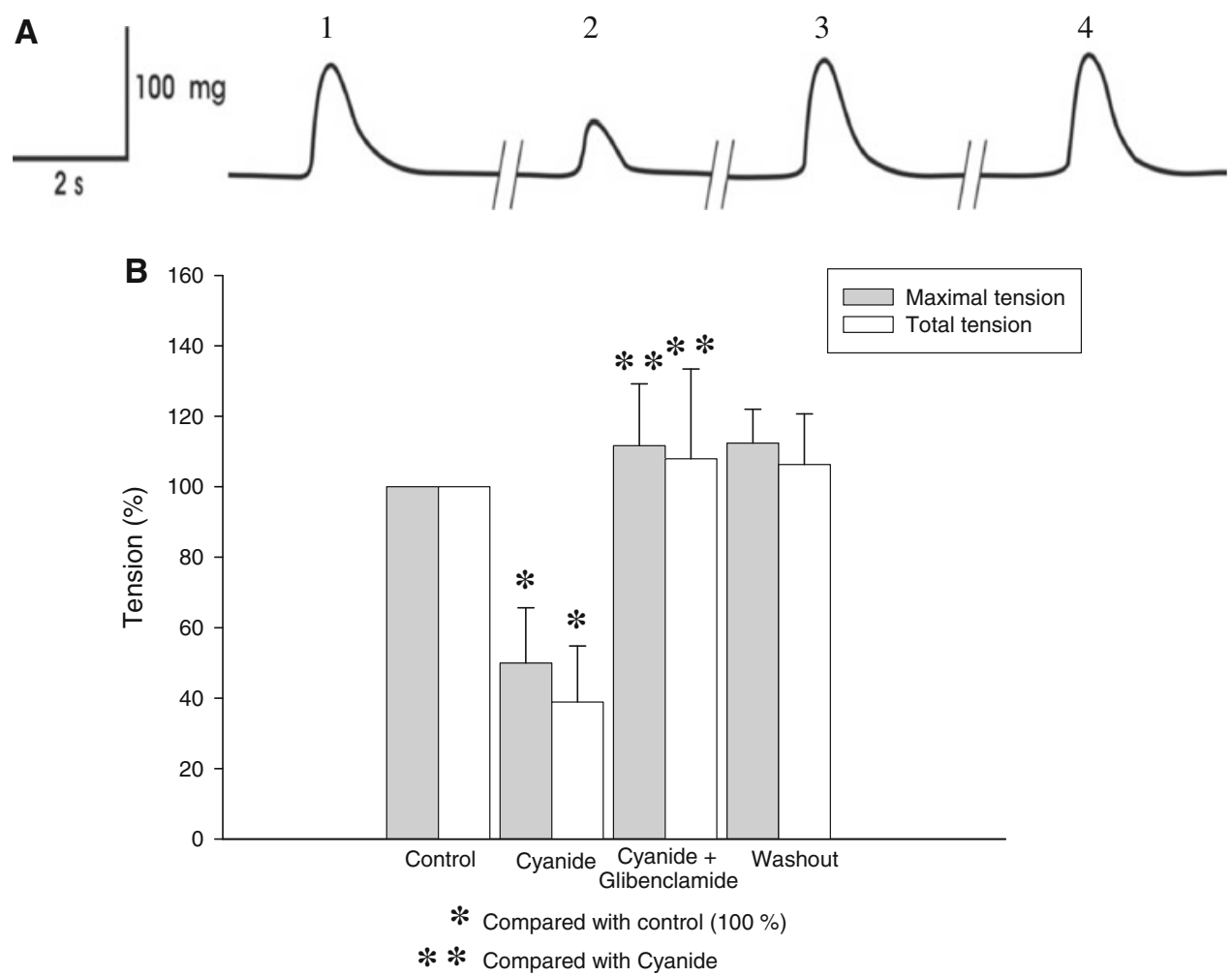

avian fast skeletal muscle fibers, and it has been suggested that this kind of channels may have a functional role in muscular fatigue. However, the physiological role of these $\mathrm{K}^{+}$channels during the fatigue process and metabolic inhibition is not yet fully established (Davies et al. 1991; Nichols and Lederer 1991; Fosset et al. 1995; Minami et al. 2004, Cifelli et al. 2007). In this paper the effect of glibenclamide (a $\mathrm{K}_{\text {ATP }}$ channel blocker, Van Lunteren et al. 1998) during low frequency fatigue was studied.

The aim of this work was to investigate the effect of glibenclamide on fatigued slow skeletal muscle of the chicken. Previously glibenclamide has been found to have a higher effect on slow-twitch muscle fiber tension than in fast-twitch muscle fibers of the chicken (Sánchez-Pastor et al. 2002). Therefore, a fatigue model for skeletal muscle fibers of the chicken was designed using simple twitch and tetanus to induce fatigue in ALD muscle. ALD muscle is a slow-twitch muscle and fatigue was induced by stimulation pulses at a frequency of $0.2 \mathrm{~Hz}$, reaching a $60-70 \%$ fatigue in approximately $60 \mathrm{~min}$ of stimulation, and by a stimulation frequency of 5 and $50 \mathrm{~Hz}$, reaching 70-80\% fatigue in $10 \mathrm{~min}$. When higher stimulation frequencies $(70,100$ and 140) were applied, as reported in other works using different experimental models (Westerblad and Allen 1991; Light and French 1994; Duty and Allen 1995; Matar et al. 2000), muscle fibers suffered irreversible damage. At the age of the animals used, ALD muscle has small physical dimensions, facilitating oxygen diffusion. Muscle and state of contraction was monitored at the beginning and at the end of the fatigue experiments through high-potassium contracture, so it could be analyzed before and after washout. Only those muscles that recovered from fatigue and from the effects of the drugs used were taken into account for analysis.

The participation of $\mathrm{K}_{\mathrm{ATP}}$ channels in the fatigue process has been studied using specific blockers but the role of these kinds of channels is still controversial (Comtois et al. 1994; Matar et al. 2000; Cifelli et al. 2007). The present work shows that glibenclamide improves muscle tension (twitch tension and tetanic tension) in the fatigued state, which coincides with previous work on mammalian fast skeletal muscle (Duty and Allen 1995). However, in the present experiments, when fatigue was induced with tetanic contractions (at high frequencies), further diminution in tension shortly after glibenclamide washout was observed. This could be from fiber damage due to the fact that $\mathrm{K}_{\mathrm{ATP}}$ channels remained closed by glibenclamide, thus avoiding the cellular protection in which $\mathrm{K}_{\mathrm{ATP}}$ channels have been involved. This situation was not observed with fatigue at low frequencies.

Moreover, it has been shown that after a fatiguing period muscle contractile capabilities are diminished (Fitts and Metzger 1988). This effect has been associated with a diminution in intracellular $\mathrm{Ca}^{2+}$ concentration (Allen 


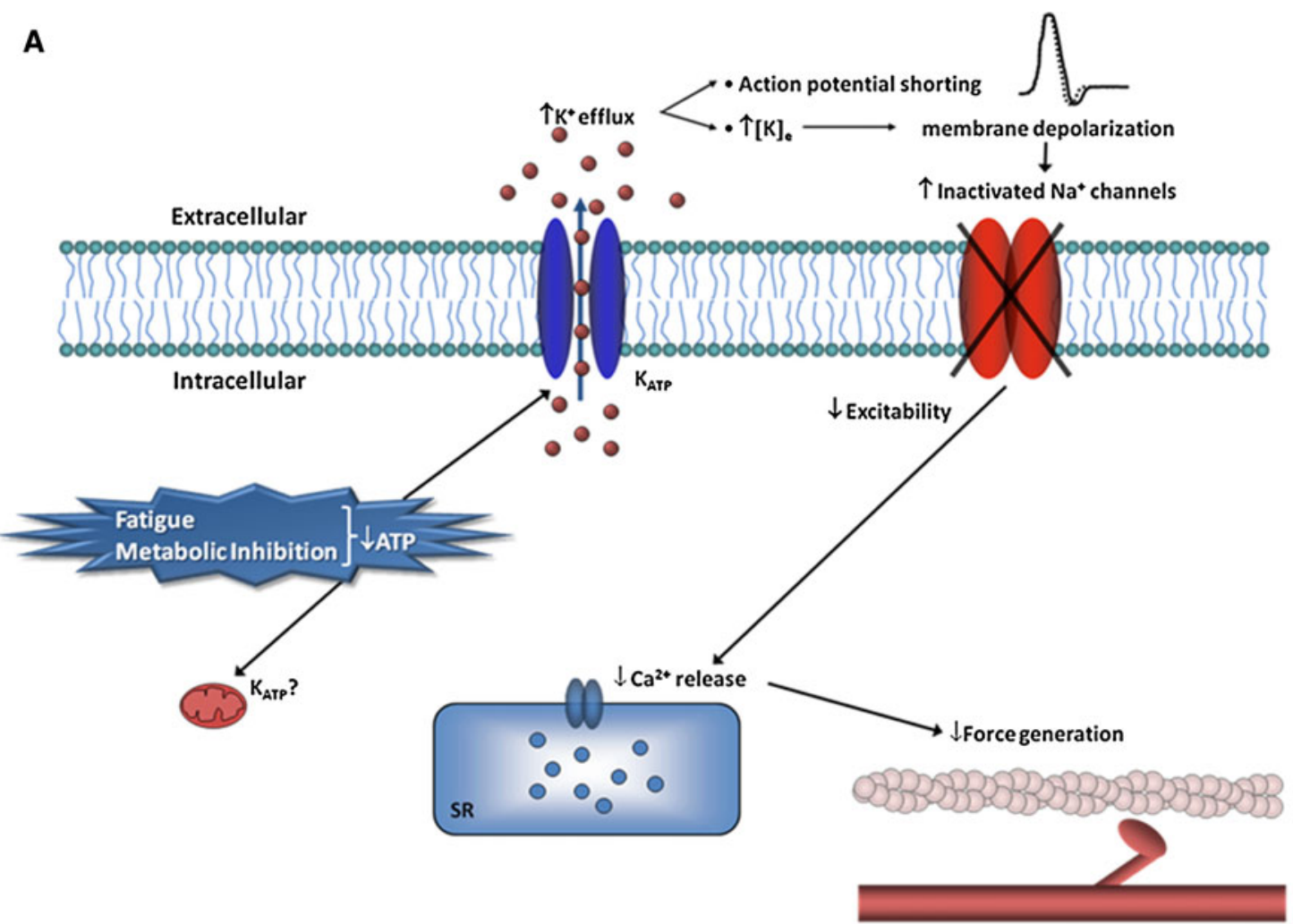

B

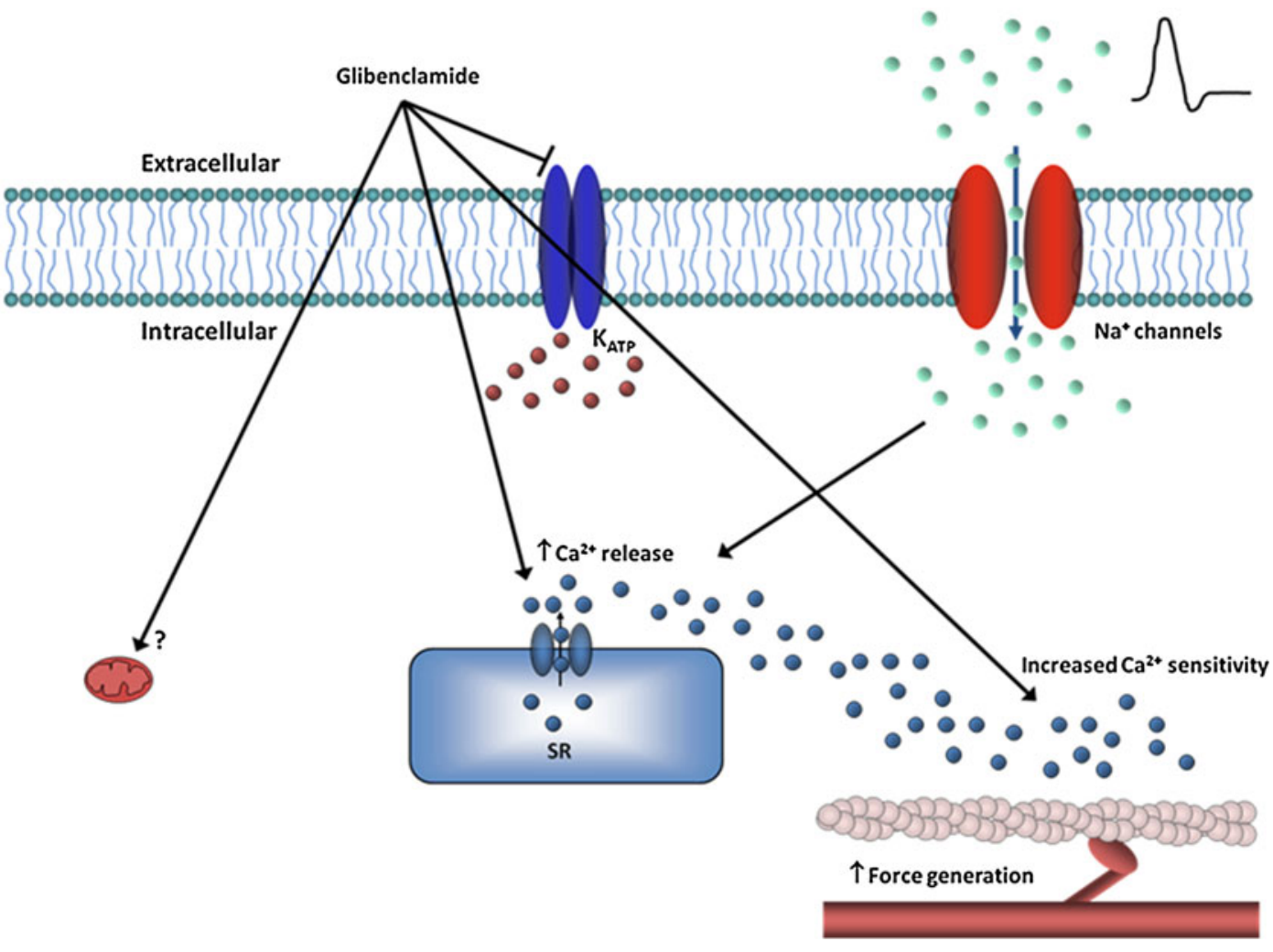

et al. 2001) affecting the excitation-contraction coupling. Thus, the effects of glibenclamide could be due to an involvement of this drug in one of the steps involved in excitation contraction coupling and in the modulation of intracellular $\mathrm{Ca}^{2+}$ during fatigue in slow skeletal muscle fibers. 
4 Fig. 6 Possible role of $\mathrm{K}_{\mathrm{ATP}}$ channels in skeletal muscle. a During fatigue or metabolic inhibition a reduction in ATP is produced leading to the opening of $\mathrm{K}_{\mathrm{ATP}}$ channels. This causes an increase in $\mathrm{K}^{+}$efflux in turn causing a shortening in the action potential. This excess in $\mathrm{K}^{+}$ efflux also increases the external $\mathrm{K}^{+}$concentration, depolarizing the membrane. Both of these processes cause $\mathrm{Na}^{+}$channel inactivation, reducing excitability. The reduction in excitability is reflected in a smaller $\mathrm{Ca}^{2+}$ release from the sarcoplasmic reticulum, causing less force generation. $\mathbf{b}$ In the presence of glibenclamide, there is a blocking of $\mathrm{K}_{\mathrm{ATP}}$ channels at the cell membrane and possibly at the mitochondria. This blocking at the cell surface avoids the shortening of the action potential and enough $\mathrm{Na}^{+}$channels can be activated causing normal $\mathrm{Ca}^{2+}$ release from the sarcoplasmic reticulum. These $\mathrm{Ca}^{2+}$ ions reach their binding sites at Troponin $\mathrm{C}$, allowing for the formation of cross bridges generating muscle contraction. Moreover, glibenclamide may increase $\mathrm{Ca}^{2+}$ release from the sarcoplasmic reticulum and increase $\mathrm{Ca}^{2+}$ sensitivity of Troponin $\mathrm{C}$, increasing force generation

The effect of glibenclamide is the improvement of tension in the fatigue state, which is attributed to $\mathrm{K}_{\mathrm{ATP}}$ channel blockade, together with an indirect effect on $\mathrm{Ca}^{2+}$ release from the SR and/or a greater $\mathrm{Ca}^{2+}$ entry (Duty and Allen 1995; Jones 1996). $\mathrm{K}_{\mathrm{ATP}}$ channel blockade by glibenclamide would reduce $\mathrm{K}^{+}$efflux from the muscle fiber leading to elongation of the action potential (Castle and Haylett 1987; Light and French 1994), which in turn would increase intracellular $\mathrm{Ca}^{2+}$ release (Duty and Allen 1995). Another possibility is that myofilament $\mathrm{Ca}^{2+}$ sensitivity is increased (Duty and Allen 1995). However, more experiments are needed to explain this mechanism.

The present work also showed that glibenclamide increases tension in caffeine contractures even when sarcolemmal $\mathrm{Ca}^{2+}$ channels were blocked, suggesting a greater $\mathrm{Ca}^{2+}$ release from the SR (Fig. 6).

On the other hand, it is known that ATP production is also diminished during metabolic inhibition (Adler et al. 1999); this diminution would be sensed by $\mathrm{K}_{\mathrm{ATP}}$ channels at the sarcolemma, which in turn would be activated causing a reduction in membrane excitability. To obtain further evidence of $\mathrm{K}_{\mathrm{ATP}}$ channel presence in this muscle and their possible role during metabolic inhibition, the muscles were stimulated repeatedly in the presence of cyanide. Tension recorded under these conditions was diminished. The effect of glibenclamide was then tested by incubating the muscles in cyanide plus glibenclamide. Glibenclamide was found to avoid the diminution in tension caused by cyanide suggesting that $\mathrm{K}_{\mathrm{ATP}}$ channel activation is involved in the action mechanism causing muscle tension reduction during metabolic inhibition. Zhang et al. (2006) reported a marked decrease in tetanic intracellular $\mathrm{Ca}_{\mathrm{i}}^{2+}$ during fatigue of single soleus fibers exposed to cyanide, and suggested that the opening of $\mathrm{K}_{\mathrm{ATP}}$ was involved in these effects.

Additionally, we cannot rule out the possibility that, as in other tissues such as those of the heart and liver (Inoue et al. 1991; Paucek et al. 1992), mitochondrial $\mathrm{K}_{\mathrm{ATP}}$ channels are present in these skeletal muscle fibers and that the effects of glibenclamide on the fatigued muscle fibers were due to an additional action of this drug on mitochondrial $\mathrm{K}_{\mathrm{ATP}}$ channels (Paucek et al. 1992; García et al. 2009). However, further experiments using a selective inhibitor for these mitochondrial channels such as 5-Hydroxydecanoate are necessary.

The use of skeletal muscle fibers of the chicken provides a useful model for the study of fatigue processes, since ALD muscle is conformed exclusively of slow muscle fibers. Moreover, this type of muscle fiber shares mechanical and electrophysiological properties with mammalian and amphibian slow muscle fibers (Trujillo et al. 2002).

Thus, indirect evidence of possible $\mathrm{K}_{\mathrm{ATP}}$ channel involvement or the stopping of excitation-contraction coupling in the reduction of tension in slow skeletal muscle fibers of the chicken produced by fatigue or metabolic inhibition processes is presented in this paper.

Acknowledgments This work was partially supported, by a grant from the Ramón Álvarez-Buylla de Aldana Fund (FRABA, to MH and XT). FA and ESP had received CONACYT fellowships. Some portions of this work formed part of the $\mathrm{PhD}$ Thesis of FA, at the University of Colima, Colima, Mexico. The authors wish to thank Mr. Ezequiel Viera for his technical assistance. We dedicate this paper to the memory of Dr. J.L. Marín.

Open Access This article is distributed under the terms of the Creative Commons Attribution Noncommercial License which permits any noncommercial use, distribution, and reproduction in any medium, provided the original author(s) and source are credited.

\section{References}

Adler M, Lebeda FJ, Kauffman FC, Deshpande SS (1999) Mechanism of action of sodium cyanide on rat diaphragm muscle. J Appl Toxicol 19:411-419

Allen DG, Lee JA, Westerblad H (2001) Intracellular calcium and tension during fatigue in isolated single muscle fibres from Xenopus laevis. J Physiol 415:433-458

American Veterinary Medical Association AVMA (2007) Guidelines on Euthanasia Formerly Report of the AVMA Panel on Euthanasia. American Veterinary Medical Association http://www. avma.org/issues/animal_welfare/euthanasia.pdf accessed 26 Jan 2010

Ashcroft FM, Harrison DE, Ashcroft SJ (1984) Glucose induces closure of single potassium channels in isolated rat pancreatic beta-cells. Nature 312:446-448

Ashford ML, Sturgess NC, Trout NJ, Gardner NJ, Hales CN (1988) Adenosine $5^{\prime}$-triphosphate-sensitive ion channels in neonatal rat cultured central neurones. Pflugers Arch 412:297-304

Burton F, Dorstelmann U, Hutter OF (1988) Single-channel activity in sarcolemmal vesicles from human and other mammalian muscles. Muscle Nerve 11:1029-1038

Caputo C (1966) Caffeine- and potassium-induced contractures of frog striated muscle fibers in hypertonic solutions. J Gen Physiol 50:129-139 
Castle NA, Haylett DG (1987) Effect of channel blockers on potassium efflux from metabolically exhausted frog skeletal muscle. J Physiol 383:31-43

Cifelli C, Bourassa F, Gariépy L, Banas K, Benkhalti M, Renaud JM (2007) $\mathrm{K}_{\mathrm{ATP}}$ channel deficiency in mouse flexor digitorum brevis causes fibre damage and impairs $\mathrm{Ca}^{2+}$ release and force development during fatigue in vitro. J Physiol 582:843-857

Comtois A, Sinderby C, Comtois N, Grassino A, Renaud JM (1994) An ATP-sensitive potassium channel blocker decreased diaphragmatic circulation in anesthetized dogs. J Appl Physiol 77:127-134

Cook DL, Hales CN (1984) Intracellular ATP directly blocks $\mathrm{K}^{+}$ channels in pancreatic $\beta$-cells. Nature 311:271-273

Davies NW, Standen NB, Stanfield PR (1991) ATP-dependent potassium channels of muscle: their properties, regulation and possible functions. J Bioenerg Biomembr 23:509-535

Duty S, Allen DG (1995) The effects of glibenclamide on tetanic force and intracellular calcium in normal and fatigued mouse skeletal muscle. Exp Physiol 80:529-541

Fitts RH, Metzger JM (1988) Mechanisms of muscular fatigue. In: Poortmans (ed) Principles of exercise biochemistry. vol 27. S Karger AG, Medical and Scientific Publishers, pp 212-229

Fosset M, Allard B, Lazdunski M (1995) Coexistence of two classes of glibenclamide-inhibitable ATP-regulated $\mathrm{K}^{+}$channels in avian skeletal muscle. Pflugers Arch 431:117-124

García MC, Hernández A, Sánchez JA (2009) Role of mitochondrial ATP-sensitive potassium channels on fatigue in mouse muscle fibers. Biochem Biophys Res Commun 385:28-32

Ginsborg BL (1960) Some properties of avian skeletal muscle fibres with multiple neuromuscular junctions. J Physiol 154: 581-598

Gong B, Legault D, Miki T, Seino S, Renaud JM (2003) $\mathrm{K}_{\text {ATP }}$ channels depress force by reducing action potential amplitude in mouse EDL and soleus muscle. Am J Physiol Cell Physiol 285:1464-1474

Gramolini A, Renaud JM (1997) Blocking ATP-sensitive $\mathrm{K}^{+}$channel during metabolic inhibition impairs muscle contractility. Am J Physiol 272:1936-1946

Huerta M, Stefani E (1981) Potassium and caffeine contractures in fast and slow muscles of the chicken. J Physiol 318:181-189

Inagaki N, Seino S (1998) ATP-sensitive potassium channels: structures, functions, and pathophysiology. Jpn J Physiol 48:397-412

Inoue I, Nagase H, Kishi K, Higuti T (1991) ATP-sensitive $\mathrm{K}^{+}$channel in the mitochondrial inner membrane. Nature 352:244-247

Institute for Laboratory Animal Research (1996) Guide for the Care and Use of Laboratory Animals. National Research Council. National Academic Press, Washington, DC

Jones DA (1996) High-and low-frequency fatigue revisited. Acta Physiol Scand 156:265-270

Klein MG, Simon BJ, Schneider MF (1990) Effects of caffeine on calcium release from the sarcoplasmic reticulum in frog skeletal muscle fibres. J Physiol 425:599-626

Light PE, French RJ (1994) Glibenclamide selectively blocks ATPsensitive $\mathrm{K}^{+}$channels reconstituted from skeletal muscle. Eur J Pharmacol 259:219-222

Light PE, Comtois AS, Renaud JM (1994) The effect of glibenclamide on frog skeletal muscle: evidence for $\mathrm{K}_{\mathrm{ATP}}$ channel activation during fatigue. J Physiol 475:495-507

Matar W, Nosek TM, Wong D, Renaud JM (2000) Pinacidil suppresses contractility and preserves energy but glibenclamide has no effect during muscle fatigue. Am J Physiol Cell Physiol 278:C404-C416

Matar W, Lunde JA, Jasmin BJ, Renaud JM (2001) Denervation enhances the physiological effects of the K(ATP) channel during fatigue in EDL and soleus muscle. Am J Physiol Regul Integr Comp Physiol 281:R56-R65

Minami K, Miki T, Kadowaki T, Seino S (2004) Roles of ATPSensitive $\mathrm{K}^{+}$Channels as Metabolic Sensors. Studies of Kir6.x Null Mice. Diabetes 53:S176-S180

Muñiz J, Huerta M, Dueñas J, Trujillo X, Elizalde A (1992) Caffeine and theophylline contractures in tonic skeletal muscle fibres of the frog. Jpn J Physiol 42:711-720

Nichols CG, Lederer WJ (1991) Adenosine triphosphate-sensitive potassium channels in the cardiovascular system. Am J Physiol 261:H1675-H1686

Noma A (1983) ATP-regulated $\mathrm{K}^{+}$channels in cardiac muscle. Nature 305:147-148

Page SG (1969) Structure and some contractile properties of fast and slow muscles of the chicken. J Physiol 205:131-145

Paucek P, Mironova G, Mahdi F, Beavis AD, Woldogiorgis G, Garlid KD (1992) Reconstitution and partial purification of the glibenclamide-sensitive, ATP-dependent $\mathrm{K}^{+}$channel from rat liver and beef heart mitochondria. J Biol Chem 267:26062-26069

Rorsman P, Trube G (1985) Glucose dependent $\mathrm{K}^{+}$channels in pancreatic b-cells are regulated by intracellular ATP. Pflugers Arch 405:305-309

Sánchez-Pastor E, Trujillo X, Huerta M, Andrade F (2002) Effects of glibenclamide on twitch and tetanic tension in chicken skeletal muscle fibres. Annual Meeting, Society for Neuroscience, A127463 Orlando, FL, USA

Shabala L, Sánchez-Pastor E, Trujillo X, Shabala S, Muñiz J, Huerta M (2008) Effects of verapamil and gadolinium on caffeineinduced contractures and calcium fluxes in frog slow skeletal muscle fibers. J Membr Biol 221:7-13

Spruce AE, Standen NB, Stanfield PR (1985) Voltage-dependent ATP-sensitive potassium channels of skeletal muscle membrane. Nature 316:736-738

Spruce AE, Standen NB, Stanfield PR (1987) Studies of the unitary properties of adenosine 5 -triphosphate-regulated potassium channels of frog skeletal muscle. J Physiol 382:213-236

Thomas SA, Hume R (1993) Single potassium channel currents activated by extracellular ATP in developing chick skeletal muscle: a role for second messengers. J Neurophysiol 69:1556-1566

Trujillo X, Huerta M, Vasquez C, Andrade F (2002) Adrenaline diminishes $\mathrm{K}^{+}$contractures and $\mathrm{Ba}^{2+}$-current in chicken slow skeletal muscle fibres. J Muscle Res Cell Motil 23:157-165

Tsuura Y, Ishida H, Okamoto Y, Kato S, Sakamoto K, Horie H, Ikeda H, Okada Y, Seino Y (1993) Glucose sensitivity of ATPsensitive $\mathrm{K}^{+}$channels is impaired in $\beta$-cells of the GK rat. A new genetic model of NIDDM. Diabetes 42:1446-1453

Van Lunteren E, Moyer M, Torres A (1998) ATP-sensitive $\mathrm{K}^{+}$ channel blocker glibenclamide and diaphragm fatigue during normoxia and hypoxia. J Appl Physiol 85:601-608

Weselcouch EO, Sargent C, Wilde MW, Smith MA (1993) ATPsensitive potassium channels and skeletal muscle function in vitro. J Pharmacol Exp Ther 267:410-416

Westerblad H, Allen DG (1991) Changes of myoplasmic calcium concentration during fatigue in single mouse muscle fibers. J Gen Physiol 98:615-635

Wickenden AD, Prior H, Kelly E, Russell K, Poucher SM, Kumar P (1996) The effects of pharmacological modulation of $\mathrm{K}_{\mathrm{ATP}}$ on the guinea pig isolated diaphragm. Eur J Pharmacol 302:79-88

Yokoshiki H, Katsube Y, Sunugawa M, Seki T, Sperelakis N (1997) Disruption of actin cytoskeleton attenuates sulfonylurea inhibition of cardiac ATP-sensitive $\mathrm{K}^{+}$channels. Pflugers Arch 434:203-205

Zhang SJ, Bruton JD, Katz A, Westerblad H (2006) Limited oxygen diffusion accelerates fatigue development in mouse skeletal muscle. J Physiol 572:551-559 